\title{
La irrupción de lo cotidiano. El relato fotográfico dle una ciudad olvidada
}

\author{
The inrush of everyday life. \\ The photographic narrative of a forgotten city
}

\section{Resumen}

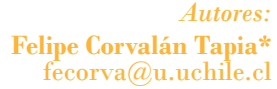

* Universidad de Chile

\section{A}

partir del trabajo del fotógrafo chileno Marcelo Montecino y su registro del Barrio Franklin, el siguiente artículo plantea una discusión sobre las posibilidades de representar la ciudad y sus transformaciones a lo largo del tiempo. Ampliando el campo de visión de las representaciones urbanas, el foco de atención de Montecino es la vida cotidiana, las marcas y huellas dejadas por la comunidad sobre los espacios que habita. Tales acciones no son valoradas como anomalías del orden urbano, sino más bien como la evidencia de una trama de significación que diversifica nuestra lectura sobre la ciudad. Así, a través de este relato fotográfico del mundo cotidiano podemos reconocer la existencia de una ciudad olvidada e incluso fallida, pero fundamental en los procesos de reconstrucción de la memoria urbana. Precisamente, la relación entre representación, espacio cotidiano y construcción de memoria, guía la discusión de este trabajo, realizado desde un perspectiva teórico-crítica.

Palabras clave: representaciones de ciudad; espacio cotidiano; fotografía documental; Marcelo Montecino.

\section{Abstract:}

With the work of Chilean photographer Marcelo Montecino and his record of the Barrio Franklin neighbourhood as its starting point, this article discusses the ways in which a city and its transformation over time can be portrayed. Expanding the field of vision of urban representations, Montecino focuses on daily life: on the marks and imprints left by the community on the spaces it inhabits. Such actions are not judged as anomalies of the urban order but rather as evidence of a pattern of meaning that diversifies our reading of the city. Thus, through this photographic narrative of daily life, we recognise a forgotten city, a flawed one even, but one that is still fundamental to the processes of reconstruction of urban memory. It is the very relationship between representation, everyday space and memory construction that guides discussion in this study, conducted from a theoretical and critical perspective.

Keywords: representations of the city; everyday space; documentary photography; Marcelo Montecino. 


\section{Introducción}

Desde los primeros años de la década del sesenta del siglo pasado, el fotógrafo chileno Marcelo Montecino comenzó a establecer una relación permanente con el Barrio Franklin, ubicado en la zona centro sur de la ciudad de Santiago. Una relación que se deja ver en un número importante de fotografías que han retratado el barrio en un arco temporal que supera los cincuenta años, tal como se puede apreciar en la exposición La máquina de coser y el paraguas. Franklin 1962-2018. ${ }^{1}$

A partir del trabajo de Montecino, a lo largo de este texto intentaremos discutir la importancia de la fotografía documental en la construcción de una memoria posible en torno a la ciudad y la vida urbana. Tal como se advierte en el título de este artículo, se trata de un registro fotográfico que pone el foco en el espacio cotidiano, permitiendo nuestra aproximación a él. Hablamos de un ámbito no siempre considerado -incluso muchas veces olvidado o desplazadopor las representaciones y registros de la ciudad. Pero pese a ello, aproximarnos a lo cotidiano resulta fundamental si queremos reconocer el grado de identificación y apropiación alcanzado por la comunidad respecto a aquellos espacios que habita frecuentemente. Como será explicado a través de las fotografías de Marcelo Montecino, en el espacio de lo cotidiano podemos leer la trama de sentidos que la comunidad teje sobre la ciudad en el tiempo. Podemos identificar huellas y signos que forman parte de aquel diálogo inacabado entre las personas y el espacio construido.

En el contexto de los estudios urbanos considerar esta mirada puede resultar relevante, pues el cruce entre fotografía y espacio cotidiano amplía nuestras lecturas y valoraciones en torno a la ciudad. Asimismo, atendiendo al Ilamado realizado desde la historiografía urbana a diversificar y enriquecer las fuentes de trabajo (Landa, 2020; Martínez-Delgado, 2020), la utilización de la fotografía urbana documental como material de análisis abre otra dimensión en la reflexión sobre la ciudad y sus acontecimientos; una dimensión que podemos caracterizar como socio-espacial, pues se interesa por la dinámica relación que se produce entre las personas y los lugares, por la experiencia en el espacio de los habitantes de una determinada área o zona de la ciudad (Lindón, 2020).

En nuestro caso particular, planteamos un análisis que se resiste a pensar en la ciudad solo como un

${ }^{1}$ Exposición realizada inicialmente en el Centro Cultural La Moneda entre diciembre de 2018 y mayo de 2019, bajo la curatoría de Andrea Aguad. Posteriormente, la muestra viajó a otras ciudades del país. Para mayor información respecto a la muestra, véase la publicación La máquina de coser y el paraguas. Franklin 1962-2018 / Marcelo Montecino (2018). hecho físico o estadístico, incluyendo en la ecuación usos, comportamientos y modos de habitar desplegados por la comunidad en el espacio. De esta manera, la fotografía es entendida como una suerte de huella material que nos habla de aquella dimensión sensible que habita entre las distintas capas que constituyen a la ciudad y los hechos urbanos.

En términos metodológicos, la investigación de carácter cualitativa que aquí se presenta responde a un enfoque teórico-crítico y propone la construcción de un marco interpretativo en diálogo con un estudio de caso: el registro fotográfico de Marcelo Montecino en el Barrio Franklin. $^{2}$

Considerando tal estrategia metodológica para una investigación todavía en curso, se expondrá, fundamentalmente, un avance de su marco teórico y un acercamiento a las fotografías de Montecino. ${ }^{3}$ Como se podrá apreciar a continuación, el hilo argumental de este marco interpretativo vincula el problema de la representación de la ciudad con la noción de espacio cotidiano y la fotografía urbana documental. A partir de tal relación se discutirán las posibilidades del ejercicio de memoria en torno a la ciudad y sus transformaciones.

\section{Representar como estrate- gia de mediación}

Antes de entrar en profundidad al ámbito de la fotografía documental urbana y al trabajo de Marcelo Montecino sobre el Barrio Franklin, vale la pena plantear aquí una breve reflexión sobre el rol de las representaciones en el campo de la arquitectura y la ciudad. Siguiendo al filósofo Nelson Goodman (2010) y su ya clásica distinción entre las artes autográficas y las artes alográficas, podemos pensar en la arquitectura, también en el diseño urbano, como acciones indirectas. Esto, en la medida en que la envergadura de las tareas acometidas por estas disciplinas dificulta que el arquitecto o planificador trabaje de 'primera mano' con aquella obra o intervención que pretende materializar.

En el texto Los lenguajes del arte, Goodman (2010) distingue entre aquellas disciplinas cuyas obras se producen en una sola fase (autográficas) y aquellas que requieren de una interfase para su ejecución (alográficas). Dentro del primer grupo podemos pensar, por ejemplo, en el pintor que pinta el cuadro o en el

${ }^{2}$ La aproximación a este caso específico no pretende solo describir sus características materiales, más bien poner en marcha un ejercicio interpretativo (Jiménez Chaves y Comet Weiler, 2016) que nos permita reflexionar sobre la mirada fotográfica de Montecino. En este sentido podemos decir que el estudio de caso de esta investigación es de carácter inductivo, pues a partir de la evidencia fotográfica se discute y teoriza, intentando comprender el trabajo observado y las problemáticas asociadas a él.

${ }^{3}$ Las fotografías reunidas en este artículo constituyen una muestra acotada del trabajo de Montecino en Franklin e incluyen registros que van desde el año 1962 hasta los primeros años de la década del noventa. La elección de estas fotografías busca acercar al lector a los distintos focos de análisis que esta obra visual nos ofrece. Desde las marcas dibujadas por los habitantes en el barrio hasta aquellos cambios programáticos deliberados que alteran el uso y sentido del espacio. 
escultor que esculpe su escultura. En el segundo caso, uno de los ejemplos más paradigmáticos es el de la música, que requiere de la mediación de la partitura para su interpretación. O el caso del guion, pues la información que contiene define la secuencia de escenas que constituyen a una obra teatral o cinematográfica. Algo similar ocurre con la arquitectura, cuyo proceso de producción -desde la gestación hasta la materialización de las obras- atraviesa distintas fases y etapas de mediación. Por tanto, la tarea del arquitecto, planificador o diseñador urbano difícilmente puede ser definida como una acción del todo inmediata.

En este contexto podemos entender la importancia adquirida por las estrategias de representación gráfica en las disciplinas proyectuales, pues estos medios comunican las decisiones tomadas por arquitectos $y$ planificadores, estableciendo un puente de conexión directo entre concepción y materialización. Nos referimos a una mediación que en términos más profundos puede ser pensada como el espacio de vinculación entre teoría y práctica. Dos ámbitos, la teoría y la práctica, fundamentales en la tarea de proyectar el espacio y la ciudad, pero no siempre bien avenidos. ${ }^{4}$

Ahora bien, más allá de esta capacidad de comunicar aquella información que contiene la voluntad de diseñador y permitir su materialización, resulta restrictivo pensar en las representaciones solo como una producción instrumental. Tal como señala Robin Evans (2011, p. 199), las representaciones determinan el campo de visibilidad ("field of visibility") del arquitecto; por cierto, también del planificador o diseñador urbano. Este marco de visibilidad no solo está relacionado con aquello que el arquitecto logra efectivamente 'ver' cuando observa la realidad, sino también al tipo de variables que incorpora en su propio ejercicio proyectual. De esta manera, este campo de visibilidad y sus representaciones está asociado a lo que el arquitecto 've', 'hace' y también a los sentidos que se ponen en juego en su diálogo permanente con aquella realidad que busca intervenir o modificar. Así, el campo de visibilidad enunciado por Evans define la manera en que el arquitecto o planificador lee y entiende la realidad.

En función de lo hasta aquí comentado, es importante señalar una cuestión que puede resultar un tanto obvia, pero que no siempre es considerada: la no neutralidad de las representaciones. Tal como sostiene Stuart Hal (2013) en el campo de los estudios culturales, o Stan Allen (2009) en el ámbito de la arquitectura y el urbanismo, las representaciones nunca son producciones neutrales. Por el contrario, las representaciones siempre están 'cargadas', siempre plantean un punto de vista que guía y orienta nuestras interpretaciones sobre aquella realidad observada.

${ }^{1}$ Al respecto, el teórico e historiador de la arquitectura Robin Evans (2011, p. 154) utiliza la expresión "translate" para referirse al rol de las representaciones en el campo arquitectónico. Se trata de una traducción que viaja, que se desplaza entre dos ámbitos distintos: la abstracción de las ideas y la materialización y construcción de las obras en el espacio. Si bien Evans centra su atención en el dibujo, sus reflexiones pueden ser extrapoladas al problema general de las representaciones en la arquitectura y las disciplinas proyectuales.
Para Stuart Hall (2013), el trabajo de las representaciones -pensadas en términos amplios- es la producción de sentido(s), la constitución de un marco interpretativo que nos permite entender el mundo, entrar en diálogo con él. Así, representar supone nombrar las cosas y los acontecimientos que forman parte de aquello que solemos Ilamar 'realidad'. Por tanto, las representaciones son producciones esencialmente activas, pues participan en la 'construcción' de ese mundo que observamos, un rasgo que dificulta su lectura como medios neutrales o meramente instrumentales.

\section{Representaciones de ciu- dad. Límites y posibilidades}

Aquella no neutralidad a la que nos hemos referido se torna especialmente evidente en el caso de la ciudad, sus registros y estrategias de visualización. Tales representaciones, sobre todo a partir del advenimiento de la Modernidad, tienden hacia la expresión del funcionamiento de la ciudad, ya sea a partir de la anticipación o bien a través de la comprobación. Es decir, a partir de representaciones gráficas que buscan predecir formas, conductas y comportamientos (anticipación); o bien mediante representaciones realizadas a posteriori, que pretenden verificar el correcto desempeño de la ciudad, de acuerdo con los planes trazados previamente (comprobación).

Más allá de sus particularidades, en ambos casos anticipación y comprobación- es posible reconocer una tendencia hacia el control, un intento de aprehensión de la ciudad y la vida urbana. En términos representacionales, tal voluntad transforma la ciudad en una imagen manipulable, dispuesta a ser intervenida una y otra vez por el técnico, por aquellos profesionales que tienen la potestad del diseño y que a través de él buscan modificar el curso del espacio urbano. Ejemplos paradigmáticos de esta forma de trabajo son aquellas representaciones de ciudad desarrolladas durante la primera mitad del siglo XX, con inclinación a anteponer la planificación sobre cualquier rasgo o cualidad preexistente. Tal es el caso de las imágenes de la High Rise City de Ludwig Karl Hilberseimer de 1924 o del emblemático Plan Voisin de Le Corbusier del año 1925.

Desde una perspectiva operativa, aquella voluntad de control que suele guiar a las representaciones de la ciudad puede parecer oportuna, incluso comprensible. Sin embargo, al trasladar la discusión al ámbito de la memoria urbana, tal aproximación resulta problemática. Esto, en la medida en que la apuesta por el control supone muchas veces una simplificación de aquellas variables que constituyen la ciudad y su complejidad, limitando nuestras posibilidades de lectura y significación en torno a ella. Pero, además, en una cuestión que resulta relevante para esta investigación, el intento de aprehensión activado por las representaciones de ciudad termina por establecer una distancia creciente respecto al espacio cotidiano y sus acontecimientos. Nos referimos aquí a un espacio fundamental en la construcción de una historia y memoria urbana debidamente situadas, pues en él se expresa el diálogo entre la comunidad y aquellos lugares habitados -también transformadoscon frecuencia. 
Llegados a este punto, es oportuno discutir el alcance del término 'espacio cotidiano', que en el contexto anglosajón es usualmente referido a partir de la expresión everyday life (Higmore, 2002; Heller, 2017). ¿¿De qué hablamos cuando hablamos del espacio cotidiano?; ¿a qué tipo de ámbito nos estamos refiriendo?; ¿qué acciones o acontecimientos podemos inscribir inicialmente en él? Al respecto, tal como señala el investigador Ben Highmore (2002), la cercanía de este espacio a nuestra propia experiencia vital no supone necesariamente que su definición sea sencilla o acotada. Por el contrario, siguiendo a Highmore podemos pensar en lo cotidiano como un espacio un tanto escurridizo, que generalmente logra escabullirse de aquellos procedimientos que buscan su control y precisión.

En esta dirección, el propio Ben Highmore añade que más allá de sus posibles definiciones, resulta adecuado pensar en el mundo de lo cotidiano como una perspectiva de entrada a la experiencia (Simi, 2018). En nuestro caso específico, a la experiencia de habitar, estar y transitar la ciudad a través del tiempo. Se trata entonces de observar y situarse en el espacio cotidiano atendiendo a las distintas variables y aspectos que lo constituyen, que en él confluyen. Desde aquellas acciones 'repetidas' una y otra vez que definen la extensión de la rutina; hasta aquellas cuestiones mucho más intangibles, asociada a la afección recíproca que se produce entre la comunidad y el espacio material (Highmore, 2002).

Precisamente, a partir de la dificultad que entraña su propia definición (Bou, 2015; Highmore, 2002), podemos advertir que la aproximación a lo cotidiano nos plantea también interrogantes sobre sus posibilidades de representación. ¿Es posible representar lo cotidiano? ¿de qué manera?; ¿a través de qué medios o estrategias? ¿qué necesidad tiene acometer este ejercicio de representación? Son algunas de las preguntas que surgen a partir de la conceptualización y observación de lo cotidiano; que como veremos a continuación están presentes en la fotografía documental que registra la ciudad y sus desplazamientos.

\section{Ampliar el campo de visión}

La voluntad de aprehensión y control exhibida por las representaciones de ciudad antes comentada encuentra un contrapunto en la fotografía documental. Una labor fotográfica que emerge con fuerza hacia la mitad de siglo XX en Europa, Estados Unidos y también en Chile; que presenta un registro más emotivo, incluso afectivo (Aubán, 2017), en torno a la vida en la ciudad. Tal registro permite develar, sacar a la luz capas de significación inicialmente olvidadas, ocultas e incluso omitidas por aquellas representaciones realizadas habitualmente sobre la ciudad.

Parte importante de este des-ocultamiento promovido por la fotografía urbana documental está asociado a la definición de su foco de atención: el mundo de lo cotidiano al que nos referíamos anteriormente. Una realidad que inicialmente puede ser leída como 'menor', pero cuya acumulación de acontecimientos supone una activación permanente del pulso de la ciudad. Específicamente, la fotografía documental nos acerca a aquellos 'micro- relatos' capaces de diversificar las grandes narraciones que intentan categorizar la experiencia de habitar la ciudad (Simi, 2018).

Son precisamente estas 'micro-historias' de lo cotidiano el objeto de observación de la fotografía de Nige Henderson en el Londres de postguerra; de Emmy Andriesse en Ámsterdam en los años cuarenta; de Antonio Quintana en el Santiago de mediados de siglo; o de Xavier Miserachs en Barcelona durante la segunda mitad del siglo $X X^{5}$

La atención propuesta por la fotografía hacia ciertas acciones o hechos inicialmente catalogados como menores puede permitir que ampliemos el espectro de aquello que consideramos digno de ser mirado. Como señala Susan Sontag (2006, p. 15), las fotografías "alteran y amplían nuestras nociones de lo que puede merecer la pena mirar". En el caso de la fotografía urbana documental y su atención al espacio cotidiano, este registro nos alerta sobre otros ámbitos de la ciudad que también merecen ser mirados, pensados.

Si anteriormente discutíamos la participación de las representaciones en la proyección de una 'nueva' realidad, ahora podemos considerar su capacidad de registrar una realidad ya existente. Una tarea para nada menos importante y que también activa un punto de vista específico -no neutral- que define el alcance del registro; sus inclusiones y exclusiones.

En esta dirección, podemos señalar que el ejercicio fotográfico propone un modo de observación particular. Tal como es planteado por Pierre Bourdieu (2003) al promover su consideración como objeto de análisis de las relaciones sociales y la producción cultural, la fotografía tampoco es un medio neutral. El registro siempre implica la elección de un 'encuadre', motivo por el cual la lectura de un determinado material fotográfico debe intentar reconocer las intenciones -implícitas o explícitas-comprometidas; reflexionar en torno a ellas.

A partir de su emergencia, la fotografía se ha consolidado como una estrategia de representación que permite registrar, también rastrear, las transformaciones materiales y socioculturales acontecidas en la ciudad (Martínez-Delgado, 2020). Por esta razón, tal medio puede ser considerado como una referencia relevante en cualquier ejercicio de memoria sobre la vida urbana. Reconociendo la importancia de la fotografía en nuestra lectura y comprensión de la ciudad, Ignasi de SolàMorales (2009, p. 124) señala que a través de este medio recibimos "indicios, impulsos físicos que dirigen en una determinada dirección la construcción de un imaginario que establecemos como el de un lugar o una ciudad determinada". Concretamente, para Solà-Morales

${ }^{5}$ Tal como señala Ignasi de Solà-Morales (2009, p. 125), a estos ejemplos podemos añadir aquella fotografía "existencialista" que se pone en marcha tras la Segunda Guerra Mundial. Siguiendo a Solà-Morales, en esta aproximación a la fotografía podemos incluir el trabajo de Henri Cartier-Bresson, Robert Capa o David Seymour. Por otro lado, más allá de la figura del fotógrafo 'extranjero' que se acerca y registra un determinado lugar, podemos pensar también en el uso de la fotografía por parte de la propia comunidad organizada, con el objetivo de representar sus barrios o aquellas zonas de la ciudad consideradas especialmente significativas (Santamaría Alzate y Giraldo Vásquez, 2020). 
(2009) las fotografías forman parte de aquella memoria acumulada que guía nuestra interpretación en torno al contexto urbano y sus distintos lugares. ${ }^{6}$

Esta continua atención de la fotografía a la ciudad nos permite reconocer en esta última una fuente inagotable de escenas que forman parte de la historia de una determinada cultura, nación o lugar. Tal como es discutido por Michael Sheringham y Richard Wentworth (2016), la propia ciudad puede ser pensada como un archivo dinámico, en constante estado de acumulación y transformación. Se trata de un archivo que se nutre, en buena medida, de acciones que tienen lugar en aquellos espacios en los que transcurre la cotidianidad.

Siguiendo las observaciones de Cecile Sachs Olsen (2016), es importante considerar que esta lectura de la ciudad como archivo conlleva a su vez la activación de otra manera de mirar el contexto urbano. Por tanto, otra manera también de representar y registrar su extensión. Una mirada capaz de abandonar la atención exclusiva a aquellas estructuras fijas o estables de la ciudad, reconociendo su inestabilidad; las diferentes capas materiales e inmateriales que la conforman. De esta manera, tal mirada de archivo en torno a la ciudad nos invita a considerar aquella no neutralidad a la que nos referíamos al hablar de las representaciones, pero ahora al momento de observar el espacio. Es decir, asumir que los espacios, los lugares que habitamos, tampoco son áreas neutrales, pues en ellos, en su materialidad, se acumulan usos y sentidos a través del tiempo.

\section{Encuentros entre lo}

\section{ordinario y lo extraordinario}

Dentro de la línea de acción de la fotografía urbana documental, podemos inscribir a una parte importante del trabajo del fotógrafo chileno Marcelo Montecino, un autor cuya obra ha sido ampliamente reconocida, sobre todo a partir de su capacidad de retratar los cambios sociales, culturales e incluso políticos acontecidos en Chile y Latinoamérica durante la segunda mitad del siglo $X X^{7}$

En sintonía con lo que hemos venido discutiendo a lo largo de este texto, especialmente significativo resulta el acercamiento de Montecino al Barrio Franklin de la ciudad de Santiago. Si bien no es el único trabajo en el que el fotógrafo recurre a la vida urbana, la persistencia en el registro sobre un mismo lugar a lo largo del tiempo da cuenta de las posibilidades de ampliar el margen de las representaciones en torno a los hechos urbanos. En el

${ }^{6} \mathrm{Al}$ respecto, el mismo Solà-Morales reconoce una estrecha relación entre ciudad y fotografía, pues: "La representación de la metrópoli en los distintos medios ha encontrado desde su origen un instrumento privilegiado: la fotografía. Nacidas técnicamente en el momento de expansión de las grandes ciudades, las imágenes de París, Nueva York Tokio, o las de los continuos habitados en el primer, segundo y terce mundo, entran en nuestra memoria y en nuestra imaginación a través de la fotografía" (2009, p. 123)

Para una visión general sobre la obra del fotógrafo, véase la publicación Marcelo Montecino. 50 Años (2012). Por su parte, para observar con mayor detención la relación entre la fotografía de Montecino y la ciudad, resulta oportuno revisar las publicaciones: Santiago: invierno-verano (2015) o Walking around (Santiago) (2015b). caso de Montecino y su lectura de Franklin, tal ampliación se produce justamente atendiendo a lo cotidiano; a aquellas acciones y signos de ocupación desplegados por la comunidad sobre los espacios que habita o transita.

El Barrio Franklin es una zona comercial y habitacional situada en el límite sur de la comuna de Santiago. E carácter del barrio se define tempranamente, a partir de la instalación en él de Matadero Municipal el año $1847^{8}$. A este hecho se suma la construcción del ferrocarril de circunvalación de la ciudad, a finales del siglo XIX y principios del siglo XX, que al pasar por el barrio a través de la estación San Diego permitió la comunicación directa entre el Matadero y el resto de la ciudad. ${ }^{9}$ Atraídos por la presencia del ferrocarril y la actividad del Matadero, irrumpen en la zona un conjunto de edificios industriales que contribuirán a la definición programática del barrio y el perfil de sus residentes: clase trabajadora y comerciante.

En la segunda mitad del siglo XX, el traslado definitivo del Matadero hacia otro sector de la ciudad y la crisis del ferrocarril supone un notorio decaimiento de la actividad industrial. Esto trae como consecuencia la aparición en el barrio de una serie de galpones en desuso que serán nuevamente activados por el comercio informal. Así, según nos acercamos a las últimas décadas del siglo XX y hasta el día de hoy, predomina en el barrio una fuerte impronta comercial. En la actualidad Franklin es sinónimo del encuentro entre actividades comerciales formales e informales y confluyen en sus calles residentes, trabajadores, comerciantes y una extensa población flotante que atesta el barrio cada fin de semana en la búsqueda de todo tipo de insumos ofrecidos por el Mercado Persa Bío Bío. Es este mundo el observado y captado por Montecino: la superposición de actos y objetos, la ocupación del espacio a través de eventos libres y espontáneos.

Marcelo Montecino persiste en su observación, vuelve una y otra vez al barrio, cuestión que le permite reunir un cuerpo importante de fotografías que se distribuyen en un amplio espacio temporal. Así queda de manifiesto en la ya mencionada exposición La máquina de coser y el paraguas, que reunió fotografías tomadas por Montecino en Franklin entre los primeros años de la década del sesenta y el año 2018. Este extenso registro nos permite identificar distintas huellas dejadas por la comunidad en el barrio, sobre él. Huellas sutiles, metafóricas y también contundentes, como la inscripción de la frase "Los obreros no deben tener hijos porque serán pobres fijos" sobre una vieja pared del barrio, fotografiada por Montecino el año 1962 (Figura 1).

${ }^{8}$ Las actividades realizadas en el lugar contribuyen a perfilar, también tempranamente, un potente imaginario en torno al barrio. En este imaginario conviven los problemas de salubridad que persisten durante el siglo XIX, el intento de modernización de la zona en su tránsito hacia el nuevo siglo y la presencia de una clase popular muchas veces mirada con desprecio por la élite. Como se puede apreciar en el trabajo de Pablo González y Macarena Ibarra (2020), este imaginario se hace evidente en obras literarias de la primera mitad del siglo XX que nos permiten reconocer la tensión entre modos de vida fuertemente arraigados y la pretensión de modernización de la ciudad incluyendo su límite sur.

9 Para entender en profundidad el proceso de consolidación de esta zona de la ciudad de Santiago, se sugiere revisar la tesis doctoral de Waldo Vila (2014) La urbanización obrera en Santiago Sur, 1905 1925. De arrabal decimonónico a periferia proletaria. 


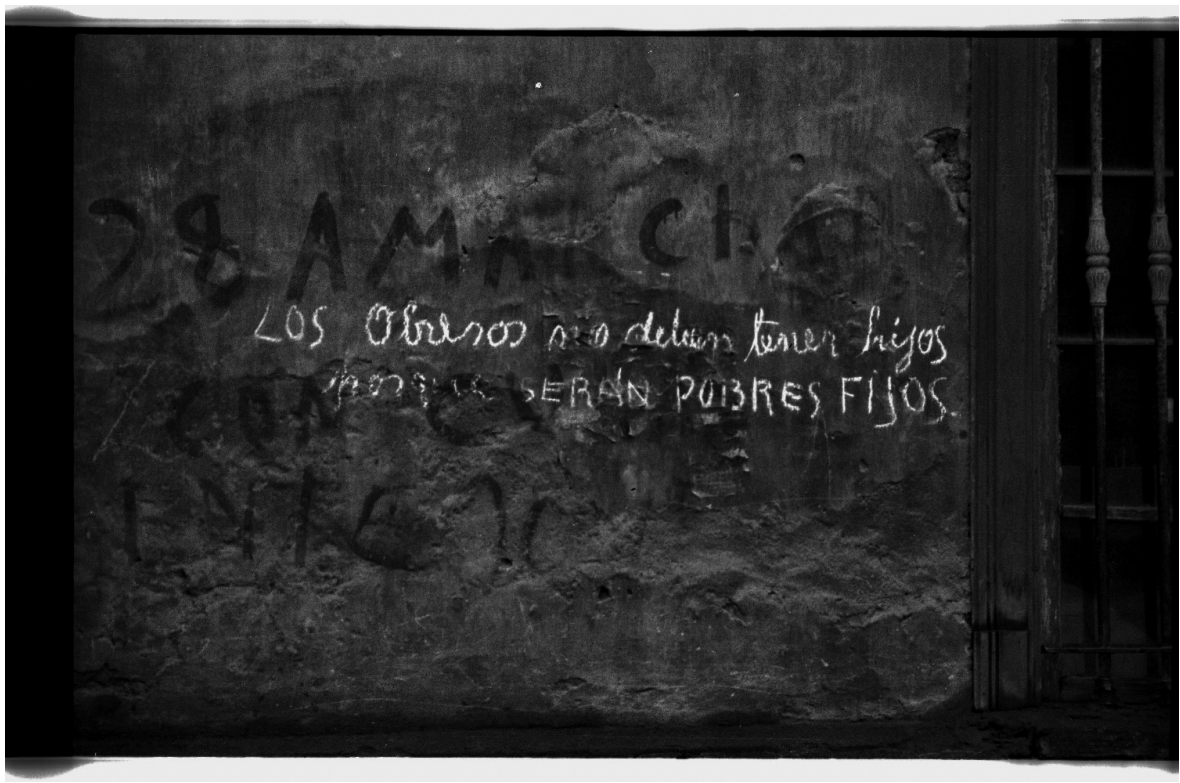

Figura 1: Fotografía de Marcelo Montecino, Barrio Franklin, Santiago de Chile, 1962

Fuente: Cortesía del autor

Si bien a partir de la consolidación de la Modernidad se advierte una tendencia hacia la 'rutinización' de los modos de vida -especialmente evidente en la ciudad a partir del siglo XIX-, la invitación de la fotografía de Montecino es a considerar lo cotidiano como un espacio que propicia el descubrimiento. Es decir, reconocer que más allá de su condición innegable de espacio próximo o habitual, en la cotidianidad también reside lo insólito, lo desconocido.

Al respecto, es oportuno detenerse en el título de la exposición antes referida, que proviene de la obra de poeta surrealista Conde de Lautréamont (2014, p. 236): "Bello como (...) el encuentro fortuito sobre una mesa de disección, de una máquina de coser y de un paraguas". Esta frase le permite a Montecino exponer la posibilidad de cruces y superposiciones inusuales entre las cosas la apertura de significados que estas coincidencias no esperadas nos ofrecen. Pero a su vez, esta mirada también tiene un alcance espacial. Así se puede observar en el registro fotográfico de acciones y usos absolutamente imprevistos, que desafían la estructura de funcionamiento preestablecida para el barrio. La transformación de una pared de esquina en escaparate ocasional de ropa interior expresa de buena manera estos encuentros insólitos a los que nos estamos refiriendo (Figura 2). En esta imagen se aprecia la intensidad con la que los habitantes del barrio se apropian del espacio y activan modificaciones en él.

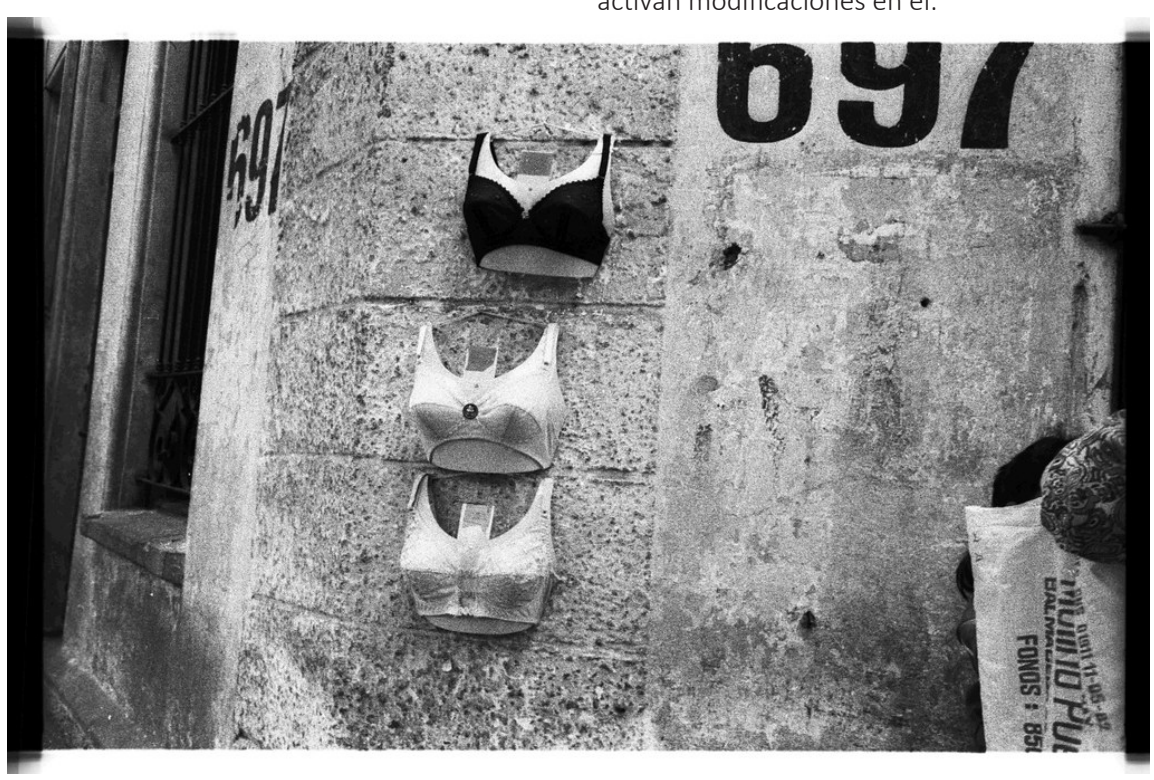

Figura 2: Fotografía de Marcelo Montecino, Barrio Franklin, Santiago de Chile, 1993

Fuente: Cortesía del autor 
Por otro lado, la evidencia de distintos tiempos de ejecución del registro fotográfico sobre un mismo lugar dinamiza nuestro ejercicio de memoria. Esto se debe a que la evocación en torno a Franklin no se activa a partir de la captura de un momento específico o puntual. Más bien, esta activación se produce en función de la acumulación de distintos fragmentos o momentos fotográficos a través del tiempo. Se trata de una acumulación que, por cierto, nos permite reconocer continuidades, pero también transformaciones y alteraciones experimentadas por el barrio durante más de cincuenta años.

Del mismo modo, estas recurrentes visitas de Marcelo Montecino a Franklin, también nos permiten elaborar una suerte de 'paisaje vital' en torno al barrio. Una reconstrucción que, tal como ocurre con la propia noción de memoria, no es simplemente dada por las fotografías, pues estas imágenes interpelan directamente a espectador. ¿Quiénes son estas personas que nos miran desde las fotografías?; ¿qué hacen?; ¿qué tipo de relación se establece entre ellas y el barrio?; ¿cómo se construye comunidad en sus acciones? Son algunas de las interrogantes que emergen desde el plano bidimensiona de unas escenas fotográficas que no están exentas de tensión (Figura 3). Nos referimos a la tensión entre lo individual y lo colectivo, que por momentos parecen confundirse en el relato fotográfico, pues los rostros anónimos no dejan de afirmar su individualidad. Pero también y, sobre todo, a la tensión que se produce entre el relato de progreso instalado en las últimas décadas en el país y la fragilidad presente en buena parte de las fotografías de Montecino. Estas fotografías exponen la evidencia de ciertas fisuras -también precariedadesque no se condicen con el relato victorioso del progreso, exhibiendo sus fallas, alertándonos sobre ellas.

Considerando la extensión de mirada propuesta por Montecino, resulta significativo que un foco de atención relevante para su fotografía sea la calle, que precisamente puede ser leída como el espacio 'ordinario' por excelencia: aquel ámbito en el que transcurre -o puede transcurrir- parte importante de nuestra experiencia cotidiana. Por otra parte, este acercamiento a la calle supone el rescate de un lugar que ha ido paulatinamente perdiendo importancia, amenazado por la creciente privatización de los espacios de encuentro (Colin, 2017). Tomando distancia de este proceso, la calle que exhiben las fotografías de Montecino es todavía un espacio de interacción espontánea, en el que convergen libremente distintas expresiones y usos. Es la calle la que acoge ocupaciones capaces de modificar su funcionalidad, de alterar la dirección y el tiempo de los desplazamientos que en ella tienen lugar. Más aún, la acumulación de objetos, formas y colores enriquece nuestra lectura estética sobre la calle y su aparente carencia de atractivo (Figura 4).

Marcelo Montecino registra en las calles aquellas acciones imprevistas a las que nos referíamos antes. También reconoce signos y estrategias de ocupación desplegadas por la comunidad sobre el espacio. En el primero de los casos -acciones imprevistas-, lo insólito es capaz de desbordar toda voluntad de predicción. De esta manera, actividades que podemos describir como 'extraordinarias' tienen lugar en el mencionado ambiente de lo ordinario. Tal es el caso de una particular escena en la que Montecino retrata a un grupo de personas trasladando un artefacto de baño por las calles del barrio (Figura 5). Recordándonos la frase de Lautréamont utilizada para dar título a la exposición de fotografías sobre Franklin, este artefacto de losa blanca funciona como fuente de emisión de significados que entran en diálogo con el barrio y sus habitantes. Una suerte de cadáver exquisito efímero, en movimiento.

Por su parte, en el caso de lo que aquí llamamos 'signos de ocupación', estos constituyen la demostración material de la apropiación puesta en marcha por la comunidad sobre los espacios que habita. Nos referimos, por ejemplo, a aquella escena en la que un conjunto de piezas o lo que parecen repuestos mecánicos, se despliegan sobre el suelo, convirtiendo a la calle en un mercado improvisado (Figura 6). Una escena que sigue ocurriendo hasta el día de hoy en el Barrio Franklin cada fin de semana.

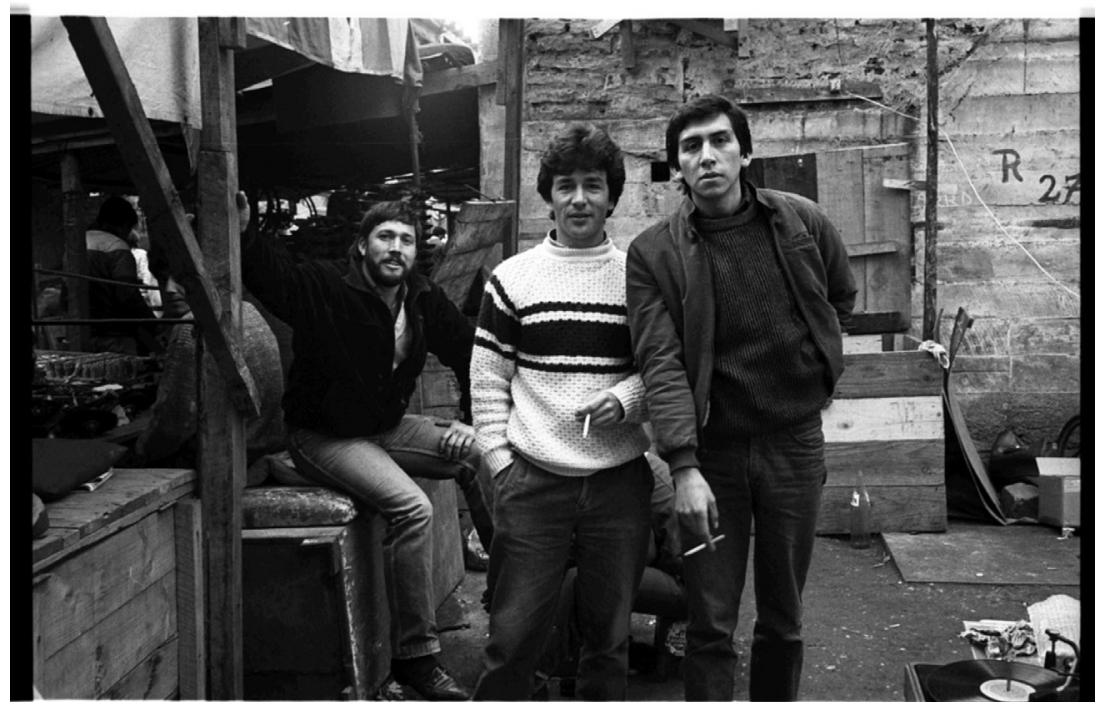

Figura 3: Fotografía de Marcelo Montecino, Barrio Franklin, Santiago de Chile, 1991

Fuente: Cortesía del autor 
ES

TO

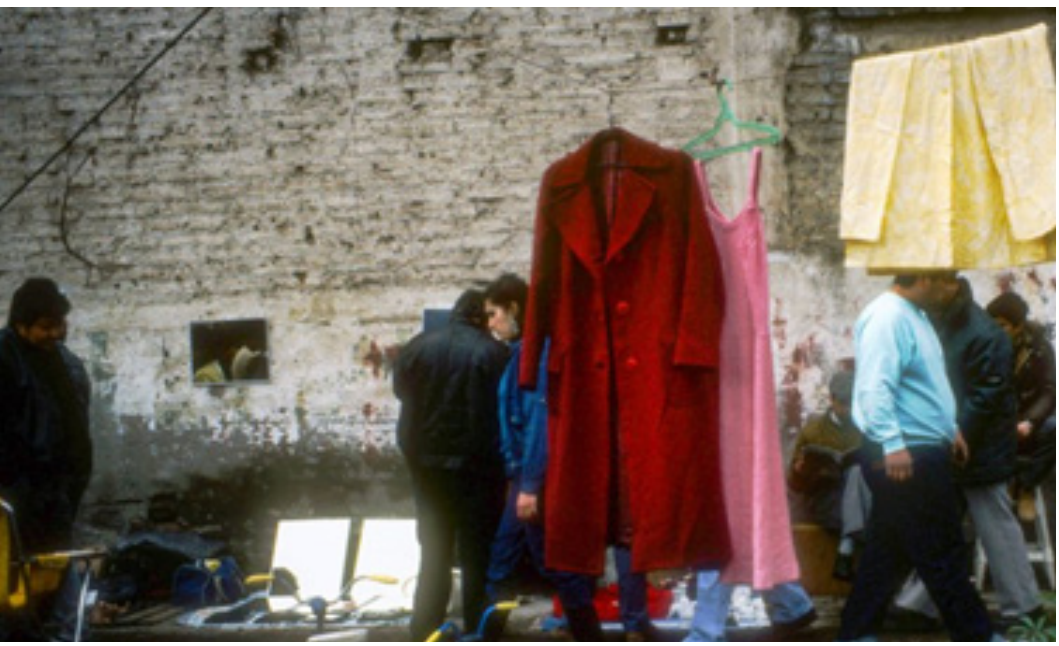

Figura 4: Fotografía de Marcelo Montecino, Barrio Franklin, Santiago de Chile, 1988 Fuente: Cortesía del autor

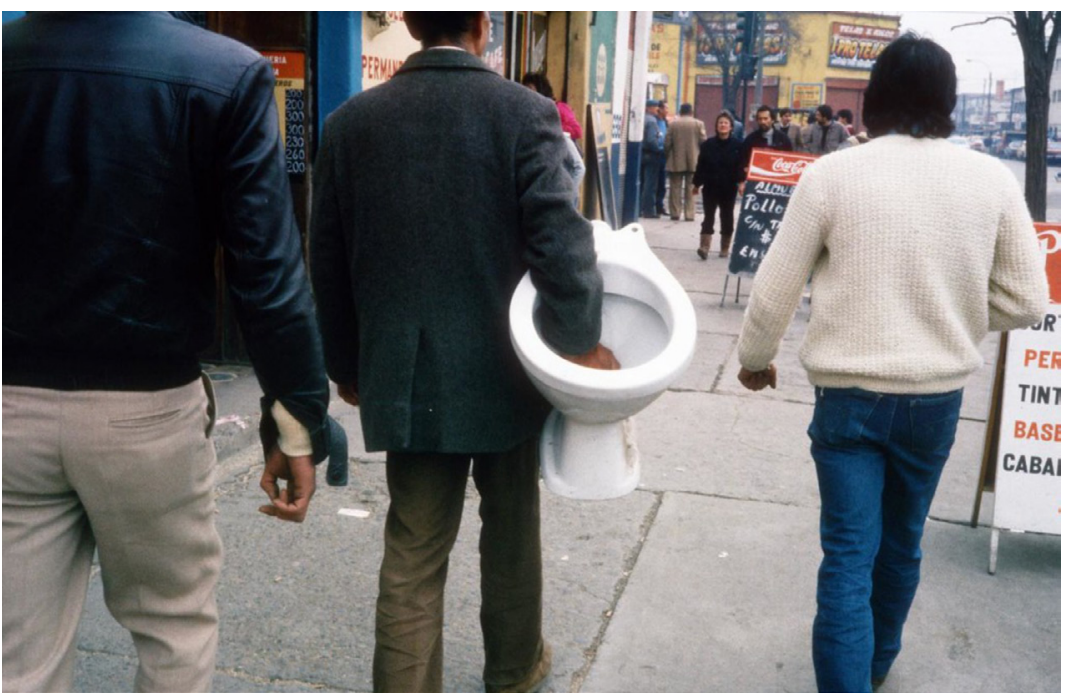

Figura 5: Fotografía de Marcelo Montecino, Barrio Franklin, Santiago de Chile, 1988

Fuente: Cortesía del autor

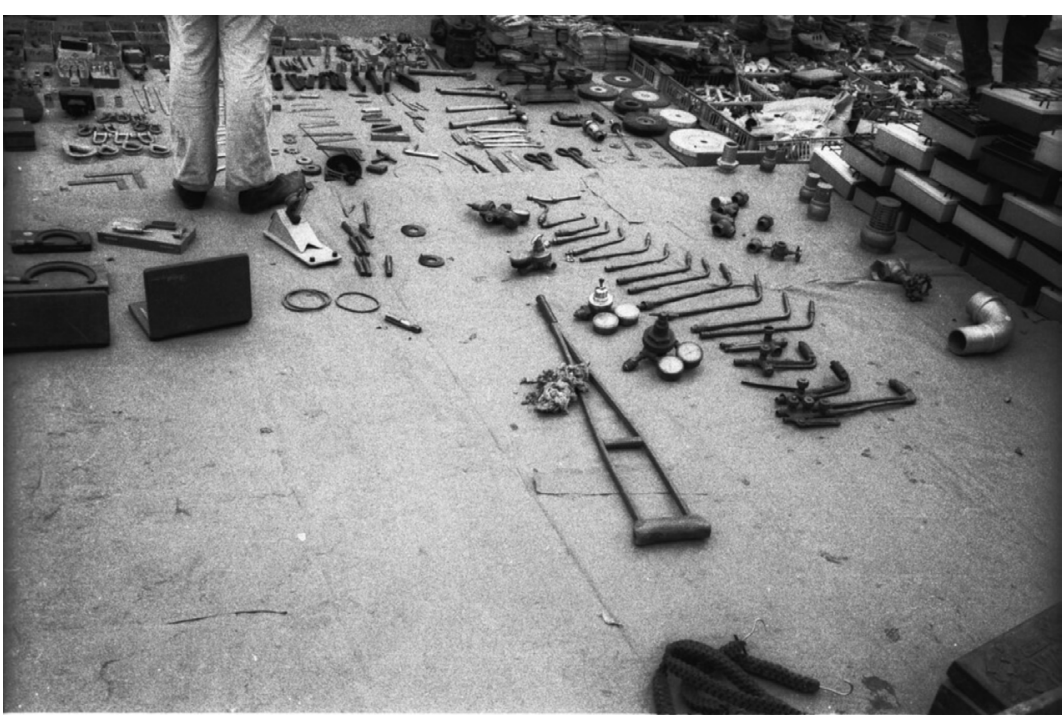

Figura 6: Fotografía de Marcelo Montecino, Barrio Franklin, Santiago de Chile, 1989 Fuente: Cortesía del autor 
Bajo la mirada de Montecino, las acciones insólitas y los signos de ocupación que se expanden en el espacio no son entendidos como anomalías que afectan el 'correcto' desempeño de la ciudad. Por el contrario, estas acciones y huellas son valoradas positivamente, pues enriquecen la experiencia de habitar cotidianamente la ciudad permitiéndonos, como espectadores de las fotografías, diversificar desde el presente nuestra lectura sobre el pasado.

\section{Consideraciones finales hacer durar la experiencia}

Siguiendo las tempranas y extremadamente lúcidas reflexiones de Walter Benjamin en torno a la fotografía, Georges Didi-Huberman (2018) reconoce en este medio la capacidad de implicarse con aquella realidad observada. La capacidad de estar en el lugar, de fundirse con las cosas, de habitar aquellos espacios registrados y a partir de tal ejecución hacer durar la experiencia. Así lo explica el propio Didi-Huberman: "Pero ¿qué significaría esto, fundirse en las cosas? Estar en el lugar indudablemente. Ver sabiéndose visto, concernido, implicado. Y todavía más: quedarse, mantenerse, habitar durante un tiempo esa mirada, en esa implicación. Hacer durar esa experiencia" (2018, p. 30).

Es precisamente esta implicación, este habitar entre las cosas, en ellas, la que podemos advertir en el trabajo fotográfico de Marcelo Montecino en el Barrio Franklin. Allí, en ese lugar, el fotógrafo transita entre la gente, entre los distintos espacios y sus elementos, permitiéndole al espectador de sus registros fotográficos 'entrar' en aquel mundo retratado, activando la extensión de la experiencia descrita por Didi-Huberman.

Evidentemente, no se trata de sugerir aquí una suerte de igualación entre la experiencia física de estar en el lugar y su observación o registro por medio de la fotografía. Se trata más bien de reconocer la capacidad de estas fotografías de acercarnos a una realidad muchas veces desconocida y ampliar así nuestra mirada en torno a la ciudad y su tránsito a través del tiempo. Como señala el propio Didi-Huberman: "Una imagen bien mirada sería entonces, una imagen que ha sabido desconectar y después renovar nuestro lenguaje y por lo tanto nuestro pensamiento" (2018, p. 31).

Más allá de su evidente y no despreciable carácter técnico, la fotografía es un ejercicio reflexivo que insta al fotógrafo -también al espectador- a tomar posición frente a lo observado. Al mirar una fotografía identificamos una imagen específica, pero al mismo tiempo entramos en diálogo con todo aquello que el registro fotográfico logra abrir, sugerir. De acuerdo a Michel Frizot (2009, p. 16) siempre podemos "sospechar" que aquella fotografía que tenemos delante de nuestros ojos "nos remite a 'otra cosa'" no necesariamente explicitada. Tal como ocurre en el caso de las fotografías de Montecino, lo evidente se expande hacia otros canales y vías de interpretación inicialmente ocultas o desapercibidas. Por tal motivo podemos señalar que observar una fotografía implica activar una mirada atenta por parte del espectador, la voluntad de desenmarañar lo que se esconde y vive tras la imagen fotográfica.

A modo de reflexión final -pero en ningún caso definitiva-, podemos decir que el cuerpo de fotografías acumuladas por Marcelo Montecino en torno a Franklin nos permite reconstruir otra memoria posible sobre esta zona de la ciudad de Santiago de Chile. Una memoria que se hilvana a partir de diferentes trazos; fragmentos de una cotidianidad que hace evidente las posibilidades de uso, transformación y apropiación de la comunidad sobre aquellos espacios que habita.

Al respecto, podemos pensar en una fotografía de Montecino que escenifica este asunto (Figura 7). En ella, el foco de atención son una serie de espejos que reflejan los movimientos en distintas direcciones de un conjunto de personas que se desplazan por el barrio. Como una suerte de metáfora del trabajo del propio Marcelo Montecino, estos espejos contienen la extensión de mirada que hemos comentado, pues la observación de un objeto material específico nos remite irremediablemente a otras escenas, a aquel cruce recurrente de acciones que tienen lugar en el Barrio Franklin.

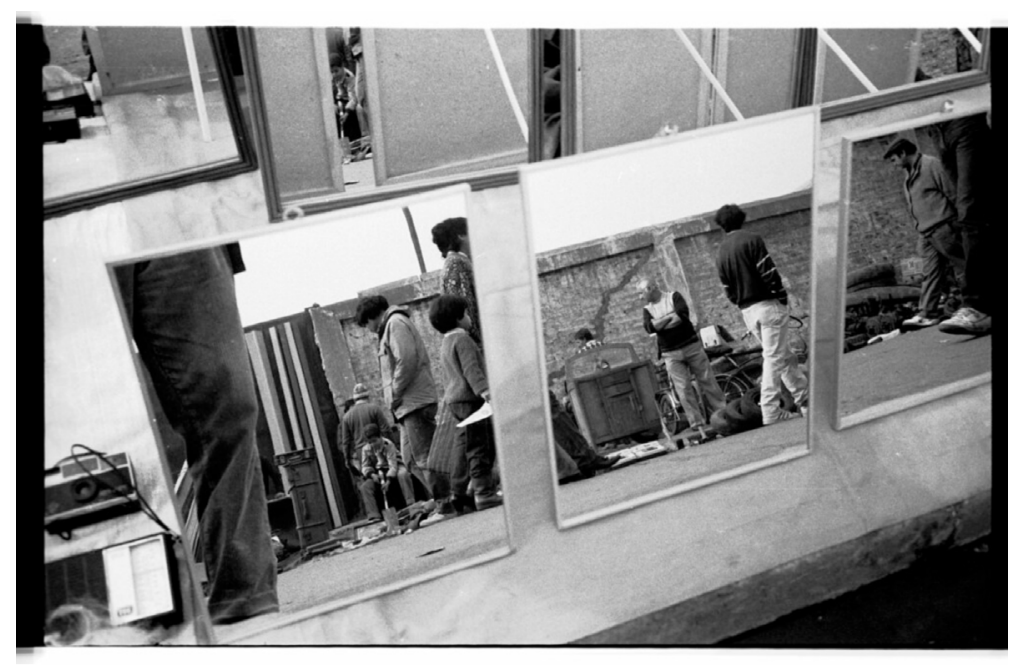

Figura 7: Fotografía de Marcelo Montecino, Barrio Franklin, Santiago de Chile, 1991

Fuente: Cortesía del autor 
Por otro lado, y desde una perspectiva estrictamente representacional, las fotografías de Montecino logran ampliar aquel campo de visibilidad enunciado por Robin Evans, referido aquí anteriormente. Esta ampliación es evidentemente material, pues se produce a través de un formato específico: la fotografía. Pero también podemos hablar de una ampliación más profunda, pues al exponer aquellas 'micro-historias' que forman parte del espacio cotidiano, se diversifica nuestra lectura en torno a la ciudad; los sentidos y significados que podemos elaborar en torno a la vida urbana (Santamaría Alzate y Giraldo Vásquez, 2020).

Así, a partir del trabajo fotográfico de Marcelo Montecino, podemos incluso repensar el alcance de la propia palabra 'representación'. Esto, en la medida en que en las fotografías aquí analizadas el prefijo 're' de la palabra representación no puede ser leído simplemente como signo de repetición o reemplazo de algo ya visto. Por el contrario, las fotografías de Montecino nos vuelven a presentar la ciudad ('re-presentar'), pero esta vez para descubrir en ella lo no advertido, las tramas de sentido que se tejen en un espacio generalmente olvidado: e espacio de lo cotidiano.

Tal como fue mencionado, la dificultad de definir qué es lo cotidiano se trasunta también en la imposibilidad de representar este espacio en toda su complejidad. Sin embargo, pese a este inconveniente y tal como es planteado por Ben Highmore (2002), sigue siendo necesario aventurarnos en la tarea de hacer visible este espacio cotidiano. Comunicar la existencia de esta cotidianidad, casi siempre ignorada por los grandes relatos que se construyen en torno a la ciudad, para de esta manera reconocer sus particularidades.

Siguiendo la invitación realizada por Highmore, la tarea parece ser promover la elaboración de estrategias de representación debidamente situadas que, aun asumiendo su condición incompleta, contribuyan a evitar que lo cotidiano y su diversidad quede en el olvido. Al respecto, probablemente un buen punto de partida sea aceptar que toda representación de lo cotidiano es siempre una parcialidad, una versión posible de un campo ilimitado. De esta manera, no se trata de pensar en las representaciones de lo cotidiano como estrategias de captura de aquello observado o vivido, sino más bien como el reconocimiento y visibilización de un ámbito fundamental para entender el pulso y las transformaciones experimentadas por la ciudad en el tiempo.

\section{Agradecimientos}

El autor del artículo agradece al fotógrafo Marcelo Montecino, quien generosamente facilitó y permitió el uso de las imágenes que forman parte de este texto, todas de su autoría.
Cómo citar este artículo/How to cite this article: Corvalán Tapia, F. (2022). La irrupción de lo cotidiano. El relato fotográfico de una ciudad olvidada. Estoa. Revista de la Facultad de Arquitectura y Urbanismo de la Universidad de Cuenca, 11(21), 69-79.

\section{Referencias bibliográficas}

Allen, S. (2009). Practice: Architecture, Technique + Representation. Routledge.

Aubán, M. (2017). La dignidad de los márgenes. Aproximaciones afectivas a la ciudad informal. Revista INVI, 32(91), 67-89.

http://revistainvi.uchile.cl/index.php/INVI/article/ view/1223

Bou, E. (2015). Representing Everyday Life. Arizona Journal of Hispanic Cultural Studies, 19, 171-181. http:// www.jstor.org/stable/43855410

Bourdieu, P. (2003). Introducción. En P. Bourdieu, Un arte medio: ensayo sobre los usos sociales de la fotografía (pp. 37-50). Editorial Gustavo Gili.

Colin, C. (2017). La nostalgia en la producción urbana: La defensa de barrios en Santiago de Chile. Revista INVI, 32(91), 91-111.

http://revistainvi.uchile.cl/index.php/INVI/article/ view/1216

Didi-Huberman, G. (2018). Cuando las imágenes tocan lo real. En G. Didi-Huberman, C. Chéroux y J. Arnaldo, Cuando las imágenes tocan lo real (pp. 7-36). Círculo de Bellas Artes.

Evans, R. (2011). Translations from drawing to building and other essays. Architectural Association.

Frizot, M. (2009). El imaginario fotográfico. Ediciones Ve.

González, P., e Ibarra, M. (2020). Cuando la periferia fue ciudad. Imaginarios y modernización urbana en el barrio Matadero (1902-1939). Revista Estudios Avanzados, 32(1), 74-93. https://doi.org/10.35588/rea.v1i32.4537

Goodman, N. (2010). Los lenguajes del arte: aproximación a la teoría de los símbolos. Espasa Libros.

Hall, S. (2013). The work of representation. En S. Hall, J. Evans y N. Sean (Eds.), Representation (pp. 1-47). The Open University, SAGE.

Heller, A. (2017). Everyday Life. Routledge.

Highmore, B. (2002). Everyday life and cultural theory: an introduction. Routledge.

Jiménez Chaves, V. E., y Comet Weiler, C. (2016). Los estudios de casos como enfoque metodológico. Academo. 
Revista de Investigación en Ciencias Sociales y Humanidades, 3(2). https://revistacientifica.uamericana.edu.py/ index.php/academo/article/view/54

Landa, I. (2020). Una aproximación a la historiografía urbana: algunos aspectos epistemológicos y metodológicos. Revista EURE - Revista de Estudios Urbano Regionales, 46(139). https://www.eure.cl/index.php/eure/article/view/3183/1306

Lautréamont (2014). Obras completas. Argonauta.

Lindón, A. (2020). La periferia: fragmentos inestables de la ciudad vivida. Perspectiva Geográfica, 25(2), 15 - 33. https://doi.org/10.19053/01233769.10548

Martínez-Delgado, G. (2020). Derribar los muros. De la historia urbana a los estudios urbanos con perspectiva histórica: propuestas teóricas y metodológicas desde un diálogo interdisciplinar. Revista EURE - Revista de Estudios Urbano Regionales, 46(137). https://www.eure.cl/ index.php/eure/article/view/2883/1243

Montecino, M. (2012). Marcelo Montecino. 50 Años. Pehuén.

Montecino, M. (2015). Santiago: invierno/verano. Ocholibros.

Montecino, M. (2015b). Walking around (Santiago). Pehuén.

Montecino, M. (2018). La máquina de coser y el paraguas: Franklin 1962-2018 / Marcelo Montecino. Ograma.

Olsen, C. S. (2016). Performing Urban Archives - a starting point for exploration. Cultural Geographies, 23(3), 511-515. https://doi.org/10.1177/1474474016638048

Santamaría Alzate, P., y Giraldo Vásquez, M. I. (2020). La ciudad como currículo y dispositivo formador. Propuesta de enseñanza del patrimonio cultural. Bitácora Urbano Territorial, 30(3), 71-82. https://doi.org/10.15446/bitacora.v30n3.79987

Sheringham, M., y Wentworth, R. (2016). City as archive: A dialogue between theory and practice. Cultural Geographies, 23(3), 517-523. https://doi. org/10.1177/1474474016646909

Simi, G. (2018). Ben Highmore: "The everyday is always a question, a problem". MATRIZes, 12(2), 113-131. http:// dx.doi.org/10.11606/issn.1982-8160.v12i2p113-131

Solà-Morales, I. (2009). Terrain vague. En I. Ábalos (Ed.), Naturaleza y artificio. El ideal pintoresco en la arquitectura y el paisajismo contemporáneos (pp. 123-132). Editorial Gustavo Gili.

Sontag, S. (2006). En la caverna de Platón. En S. Sontag, Sobre la fotografía (pp. 13-44). Alfaguara.

Vila, W. (2014). La urbanización obrera en Santiago Sur, 1905-1925. De arrabal decimonónico a periferia proletaria [Tesis de Doctorado, Pontificia Universidad Católica de Chile]. https://repositorio.uc.cl/handle/11534/21369 